\title{
Relationship between Logistics Firm Size and Business Diversification: An Empirical Study of Chongqing, Area in China
}

\author{
Nannan He ${ }^{1,2}$, Wanshan Wu ${ }^{1,2}$, Sijing Liu ${ }^{1,2,3^{*}}$ \\ ${ }^{1}$ School of Transportation and Logistics, Southwest Jiaotong University, Chengdu, China \\ ${ }^{2}$ National Engineering Laboratory of Integrated Transportation Big Data Application Technology, Chengdu, China \\ ${ }^{3}$ National United Engineering Laboratory of Integrated and Intelligent Transportation, Chengdu, China \\ Email: ^liusijing@swjtu.edu.cn
}

How to cite this paper: He, N.N., Wu, W.S. and Liu, S.J. (2021) Relationship between Logistics Firm Size and Business Diversification: An Empirical Study of Chongqing, Area in China. Open Journal of Statistics, 11, 1-18. https://doi.org/10.4236/ojs.2021.111001

Received: December 7, 2020

Accepted: January 2, 2021

Published: January 5, 2021

Copyright () 2021 by author(s) and Scientific Research Publishing Inc. This work is licensed under the Creative Commons Attribution International License (CC BY 4.0).

http://creativecommons.org/licenses/by/4.0/

\section{(c) (i) Open Access}

\begin{abstract}
This paper aims to explore the relationship between logistics firm size and business diversification, especially in micro- and small-sized enterprises, and assess the diversification process of Chongqing logistics enterprises using new data source. It is intended to contribute to theoretical research on diversification in the emerging logistics industry based on resource-based view (RBV) and factor production theory. We innovatively establish the logistics business classification system, then measure the degree and direction of diversification of logistics enterprises based on mean narrow-spectrum diversification-based product count methods. The empirically shows that there are a growing number of highly-diversified logistics enterprises in general, with an average annual increase of $14.23 \%$. Especially after 2008 , small and medium-sized enterprises developed towards related diversification while micro-sized enterprises came to the opposite conclusion. For them, creating unrelated diversified business is a crucial way to generate a competitive advantage. Unlike the conclusions derived from other industries, small-sized logistics enterprises are prone to try a new business, both related and unrelated, for better survival and performance. And changes in the firm size of medium and large-sized enterprises have little impact on the development of the business diversification.
\end{abstract}

\section{Keywords}

Business Diversification, Logistics Firm Size, RBV, Logistics Business Classification System

\section{Introduction}

The logistics industry is a composite service industry integrating transportation, 
warehousing, and information related industries, which have the foundation and inherent advantages of diversified operations [1]. Logistics enterprises are facing increasing uncertainty during the development of diversification strategy. On the one hand, the economy and total logistics amounts grew at a snail's pace, which will further intensify market competition and force some of them to transform and upgrade while others inadaptable to the market changes are to withdraw from the market. On the other hand, the demand readjustment also promotes logistics enterprises from a single function-based to integrate service providers. Finally, the shortage of land for logistics warehousing and high fuel prices, together with increasing labor costs and environmental protection costs, have caused the operating costs of Chinese logistics enterprises to rise and profits to drop significantly, further increasing the survival pressure of logistics enterprises, and even withdrawal from the logistics industry. Thus, uncertain factors of diversified development for logistics enterprises have increased. Meanwhile, due to the rapid development of diversification strategy of logistics enterprise in various countries, it is in urgent need of theoretical support. Research shows that many logistics enterprises in Europe, the United States, Singapore and other countries are willing to carry out diversification to meet the challenges against the background of introducing competition mechanism, market opening and increasing popularity of e-commerce. As the largest emerging logistics market since joining the WTO in 2001, China began to entirely reduce the entry threshold for foreign logistics enterprises in 2005. As a result, competition in the logistics market became fierce, and logistics enterprises have shown a trend of diversified development. Large logistics enterprises, such as Manbang Group, Transfer Logistics, SF Express, have implemented diversification strategies in the real estate industry, commerce, information industry, and financial industry through mergers, acquisitions/alliances or joint ventures, achieving scale expansion and profitable growth. However, many small- and medium-sized enterprises (SMEs) are under tremendous pressure to maintain their competitiveness in domestic and international markets [2]. Also, they have experienced many obstacles and failures in diversification, which has led to poor survival.

In terms of research on influencing factors on the business diversification: Firm size is considered to be closely related to resources and is an important factor when choosing a corporate growth model and strategy. The continuous increase in the firm size will generate surplus public resources, which leads the organization to explore more areas and provides the basis for diversification. However, studies in service industries such as banking and insurance do not consider the impact of firm size as an endogenous influence on diversification, and simply use size as a control variable when studying the performance of diversification strategies. The few related studies have only analyzed the impact of firm size at a theoretical level based on resource-based theory, and lack of quantitative analysis. In the logistics industry, firstly, most of the existing studies use entropy index and the Herfindahl index to measure the degree of diversification, 
which requires the number of business involved and the degree of contribution of each business to the sales revenue of the enterprises. In fact, applying a firm's accumulated resources and proprietary capabilities during the scale expansion into a new market by diversification strategy can enhance its financial performance [3] [4]. Considering the differences in the development path of diversification for different-sized firms, the relationship between firm size and diversification, as the significant factor affecting economic performance and sustainable development of enterprises [5], being the research subject in this paper.

Carved in above, this paper selects 5923 existing logistics enterprises registered in Chongqing from 1984 to 2016 as a research sample to quantify the correlation between logistics enterprises of different scales and business diversification. The contributions of this article include: Firstly, this paper established a logistics business classification system (LBCS) based on CIC codes, combined with mean narrow-spectrum diversification (MNSD)-based business count methods to classify businesses and measure the diversification of the enterprise. The LBCS presented in the study can be used as a framework for future studies on the diversification of logistics enterprises in different regions at different scales. Secondly, this paper mainly focuses on the diversification process of $1535 \mathrm{mi}$ cro-sized logistics enterprises and 3757 small-sized logistics enterprises. This paper examined not only the extent but also the type and direction of diversification, with 33 years of the observation period. The results may function as a reference to strategy and policy suggestions for business managers aiming to increase their competitive power and sustainable development. Hence, this study contributes to an extension of existing literature in diversification by highlighting the role of SMEs and even micro-sized logistics enterprises, providing an exciting perspective for diversification research.

\section{Literature Review and Research Hypotheses}

\subsection{Firm Size and Business Diversification}

Based on "factor production theory", the firm size reflects the full extent of available production factors such as labor force, means of labor, subject of labor, and other resources. The optimized allocation of production factors and resource deployments among businesses is the primary component of corporate strategy [6]. Diversification is one of the good examples of corporate-level strategy, which is driven by resources [7]. In this paper, business diversification refers to a firm simultaneously operates several different businesses, which requires allocating and utilizing accumulated resources and capabilities among business to the fullest extent possible based on the identification, development, cultivation, and promotion of heterogeneous resources [8].

In practice, some studies show that the sharing of both tangible and intangible resources accumulated in the scale expansion promotes diversification [9] [10]. Besides, the results of empirical research in agriculture, manufacturing, and service industries have shown that the firm size can have a significant impact on the 
degree of related and unrelated diversification [11] [12]. That is to say, due to the competitive advantage from resources, large enterprises are more diversified, and the survival status of it is better compared with the small enterprises. Hence, our research stems from the vision of better sustainable development in logistics enterprises, so we investigate the relationship between firm size and diversification.

\subsection{The Relationship between the Size of Logistics Enterprises and the Degree of Business Diversification}

The resources owned by logistics enterprises include concrete equipment, warehouses, vehicles, and other resources, as well as intangible organizations, technologies, and reputations. In terms of the created services, it can be divided into related essential services such as transportation and storage and unrelated value-added services such as sales and supply chain solutions for the logistics industry [13]. The firm size reflects the firm's resources, which is the basis and guarantee of diversification, thus influencing the degree of diversification of the firm [14]. Also, the difference in resources between different business units reflects the degree of corporate diversification [9] [15]. Moreover, a firm's investment and services capability is also limited by the firm size. The representative views about the relationship between logistics enterprise size and diversification include: 1) Firm size determines the business scope of logistics enterprises by affecting their investment in infrastructure and information technologies. For larger sized logistics enterprises, diversifying into related and unrelated areas may be a crucial way for development and competitiveness. Thus the degree of related and unrelated diversification is higher. Due to the financial limits, Smaller enterprises may concentrate on the local market, providing relevant services to meet customer needs to increase profitability as well as market value [16];2) Yusufoglu [14] argues that the size of an enterprise can affect its access to the market and limit its ability to serve. Logistics enterprises with weak service capabilities are increasingly keen to focus on niche markets to operate related diversification businesses. In contrast, for logistics enterprises with a higher service level, developing a diversified economy and ensure all-round development, such as "one-stop" logistics services, surpasses absorbing in the core business. In general, the current literature supports the correlation between size and the degree of diversification. This is also following Martha's view [17]. Thus, firm size is an essential factor that is invaluable for a firm's diversification.

Based on the above discussion, the following hypotheses are proposed:

H1a: Firm size will be positively associated with related diversification.

H1b: Firm size will be positively associated with unrelated diversification.

\subsection{Relationship between the Degree of Business Diversification and Logistics Enterprises of Different Sizes}

Different-sized enterprises have distinct capabilities that enable them to allocate and transfer different resources variously, forming different diversification evolutionary patterns and strategies [18] [19] [20]. So it is appropriate for assessing 
the various diversification measures of different-sized companies.

Large-sized companies have performed well and have maintained a competitive edge in terms of resources and capabilities in the market. Moreover, the resources such as skills and knowledge acquired in one business can be applied to solve problems and exploit opportunities in new areas by related diversification strategy, improving their market competitiveness [21]. At the same time, an unrelated diversification strategy has the advantage of absorbing investment risks and achieving economic value in the process of scale expansion. Based on the above analysis, we assume that:

H2a: There is a significant correlation between the size of large logistics enterprises and the degree of related and unrelated diversification.

According to the research of Andersson [22], logistics alliances can enable enterprises to integrate, share the capabilities, resources as well as risks with each other. So the members of alliances can quickly expand their business into related and unrelated areas to achieve economies of scale and scope [16] [23] [24]. This is a joint development path for small and medium-sized logistics companies [25] [26]. In China, since convenience for joining the logistics alliances provided by continuous development of the network information technology together with the solid customer base in a niche market, the resources and capabilities of managing a variety of business accumulated in the scale expansion can be utilized by related and unrelated diversification strategy which also help small- and medium-sized firms operate more effectively [27]. We believe that:

$\mathrm{H} 2 \mathrm{~b}$ : The size of medium-sized logistics enterprises will be positively associated with the degree of related and unrelated diversification.

H2c: The size of small-sized logistics enterprises will be positively associated with the degree of related and unrelated diversification.

Due to insufficient resources such as physical, human, or organizational capabilities, micro-sized logistics enterprises have weak strength in the 800 billion less-than-truckload (LTL) market in China [28]. For one thing, as the "escape hypothesis" suggests that firms that experience poor prior performance in current industries are likely to prefer unrelated diversification [29] [30]. For another, compared with tangible resources with higher transfer costs and limited scope economic effects, the cost of transferring or integrating intangible resources is lower, which is the growth path of micro-sized enterprises to avoid industry barriers and risk, obtain superior performance and market advantages [20] [31]. Lastly, with the continuous development of the platform economy integrating manufacturing and service industries is emerging [32]. Many companies rely on JD- and Alibaba-based platforms to transfer or acquire intangible resources at lower entry costs. Therefore, micro-sized enterprises with flexibility and a quick decision chain can leverage and invest intangible resources into unrelated areas [21]. We assume that:

$\mathrm{H} 2 \mathrm{~d}$ : There is no significant correlation between the size of micro-sized logistics enterprises and the degree of related diversification. There is a significant 


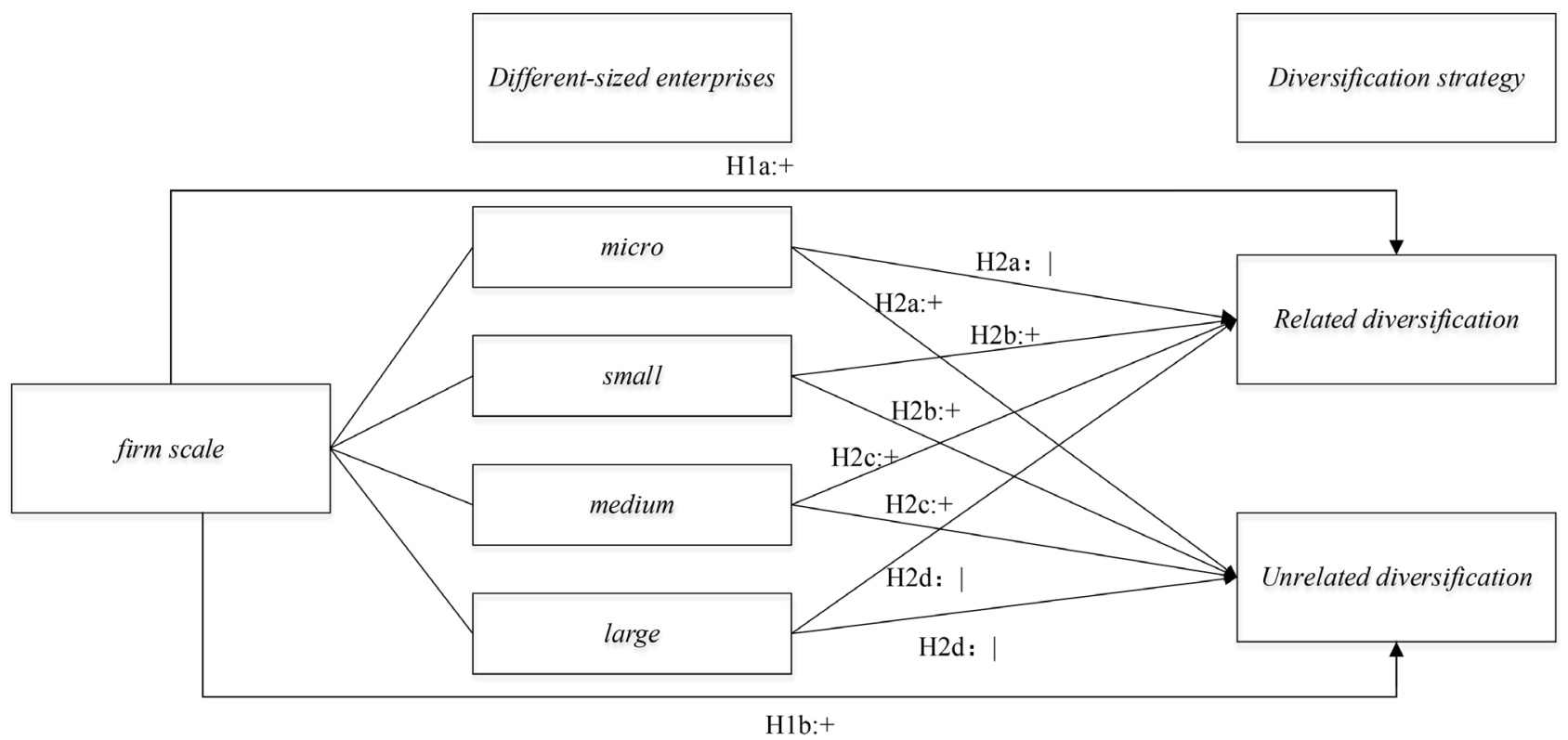

Figure 1. Conceptual Model of the relationship between firm size and business diversification.

positive correlation with the degree of unrelated diversification.

Based on the above assumptions, the research framework of this paper is shown in Figure 1.

\section{Research Methodology}

\subsection{Data Collection and Sample Design}

This research derived from the National Enterprise Credit Information Publicity System (NECIPS), an official database that includes information of all business registered establishment in China, which is constructed by the State Administration for Industry and Commerce (SAIC) in recent years driven by the internet economy. This paper mainly selected "logistics" as the keyword and acquired data on 7012 logistics enterprises registered in Chongqing from 1982 to 2016. We deleted unusable or incomplete data; the final data set consisted of 5923 valid samples. The main attribute includes company name, registered address, business unit, registered capital, business type, and other information. These data are of authority, reliability, and accuracy, but they were not open to the public until 2014, and empirical research based on this did not be used until 2018 [33]. As the only municipality directly under the central government in the western region of China, the development of logistics enterprises is under tremendous pressure to transform. Of course, as a China-Europe logistics hub under the Belt and Road Initiative, Chongqing's logistics market has expanded, and the development environment has improved significantly. Choosing Chongqing as the object of the study will play an exemplary role in representing the china logistics market.

\subsection{Logistics Business Classification System}

Business diversification is usually measured by objective methods built on estab- 
lished classification systems in which each of a firm's establishments is classified according to its primary classification or activity. The logistics industry, a typical composite industry with economic activities scattered in different industry codes, is not included as a separate category in the CIC. Therefore, the previous research is inconclusive and has led to a need for establishing a particular Logistics business classification system to extend and support the researches. Based on the logistics industry classification in the logistics cluster [34], the logistics enterprise's businesses can be divided into two categories: related businesses and unrelated businesses. Then, this paper builds a logistics business classification system based on the Chinese Industrial Classification (CIC) of Economic Activities (GB/T4754-2017), as shown in Table 1.

According to China's "Logistics Terms" (GB/T18354-2006), the related business of logistics enterprises is divided into transportation, warehousing, loading, and unloading, distribution processing, express delivery, and port services. In terms of the division of unrelated businesses, according to the Chinese State Council's Medium and Long-term Plan for the Development of the Logistics Industry (2014-2020), the unrelated businesses of logistics enterprises are divided into infrastructure and operations, information consulting services, supply chain services, multimodal transportation, sales and recycling logistics. According to the nature of the related and unrelated business combined with the rules of CIC, the category can be divided into different sub-categories.

\subsection{Measurements}

1) Business diversification

Objective methods are the most common measurement index of diversification in research on strategic management and industrial organization [35]. The objective methods have the advantages of standardization, objectivity, and replicability. Considering that research samples are mostly micro-, small- and medium-sized logistics enterprises whose information is not fully disclosed, based on the logistics business classification system, this paper uses the mean narrow-spectrum diversification (MNSD)-based business count methods to measure the degree of diversification which does not require data on sales or revenues of businesses but still provides insights into both the degree of diversification and its direction [36]. The calculation formula is:

$$
d r=\frac{d}{d u}=\frac{M}{N}(N \neq 0, M>N)
$$

where $d$ indicates the total degree of diversification of logistics enterprises, $d u$ indicates the degree of unrelated diversification, and $d r$ indicates the degree of related diversification. $M$ is defined as the number of four-digit industry a firm operates in. $N$ indicates the number of two-digit CIC codes in which a firm concurrently participates. Using $d u, d r$ as two dimensions of a four-lattice cell-matrix, to divide the degree of corporate diversification into four groups, as shown in Figure 2. 
Table 1. Classification of logistics business based on CIC of economic activities.

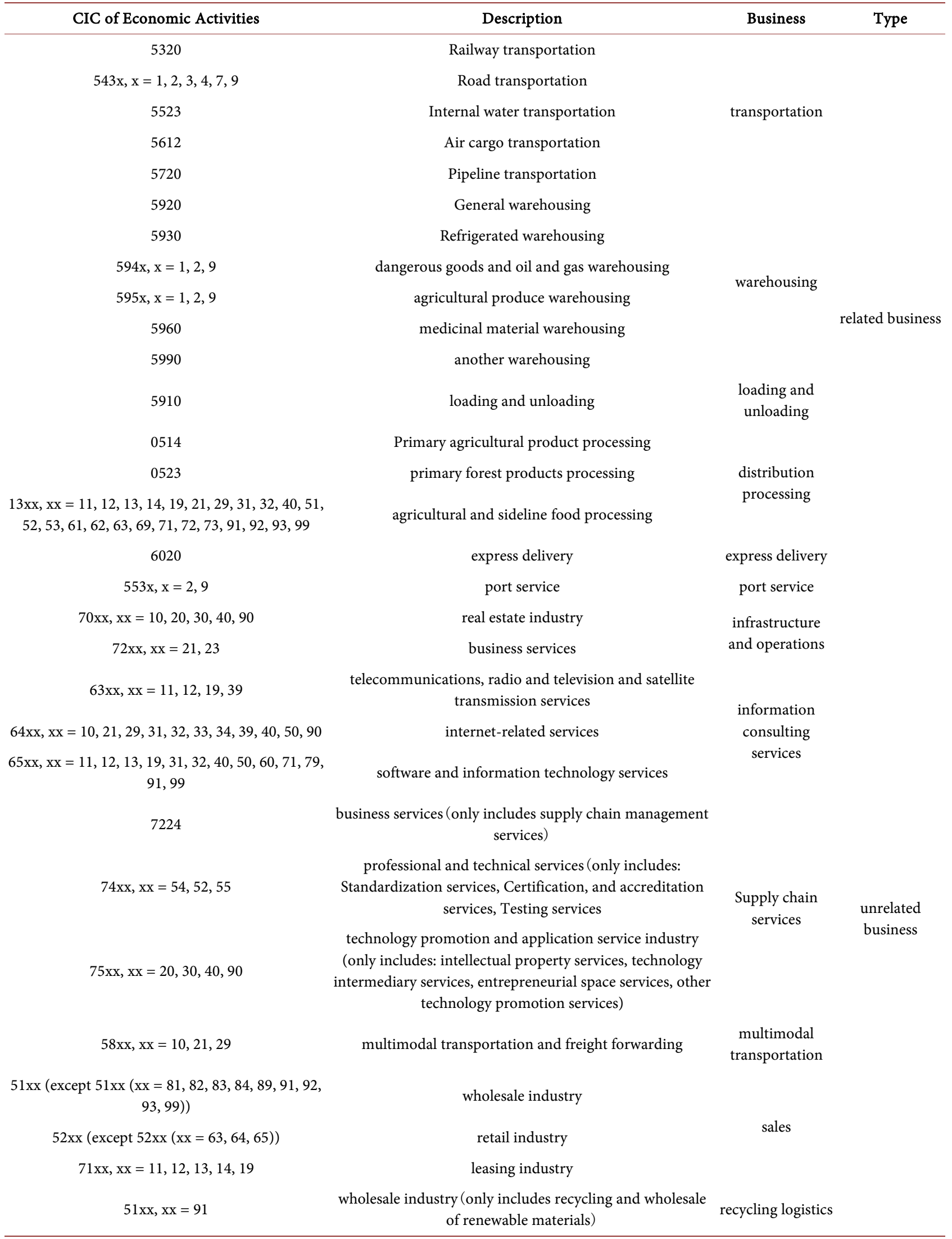




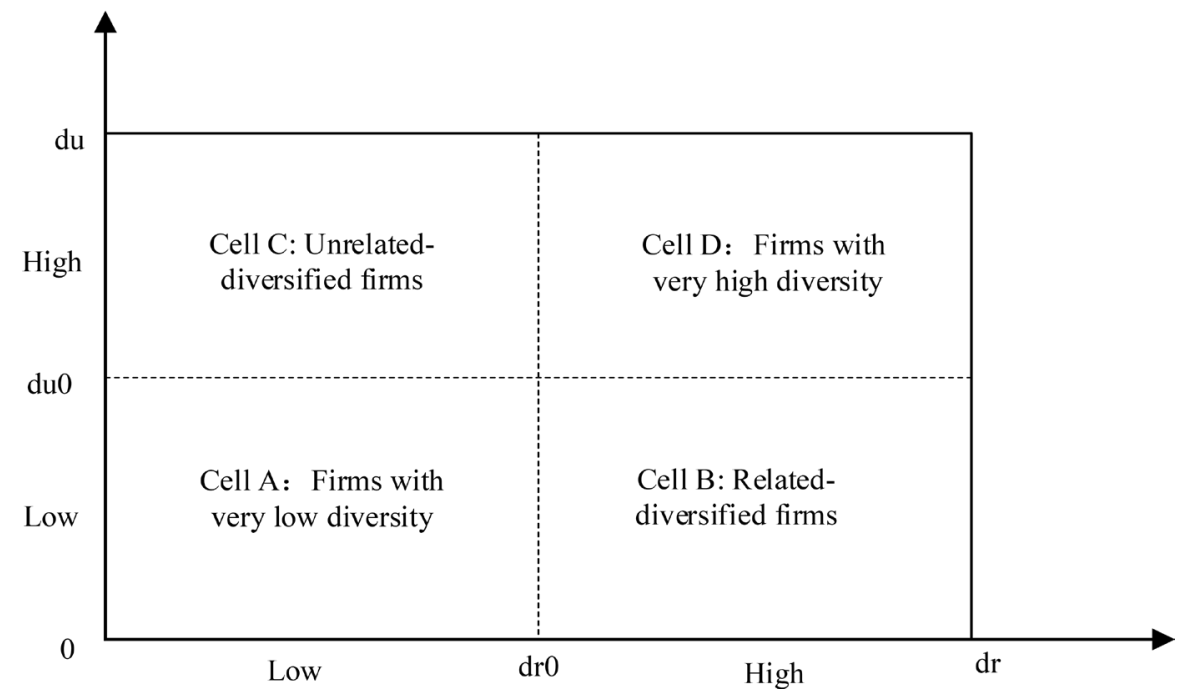

Figure 2. A two-dimensional categorical conceptualization of firm diversity.

The low-diversification group refers to logistics enterprises with low unrelated and related diversification. The high-diversification group refers to logistics enterprises with high related and unrelated diversification. The related diversified group refers to logistics enterprises with a high degree of related diversification but a low degree of unrelated diversification. The unrelated diversified group refers to logistics enterprises with a low degree of related diversification but a high degree of unrelated diversification.

2) Firm size

According to domestic and international studies, scholars mainly select EMPL (total number of employees), SALES (sales revenue), and ASSETS (total assets) as indicators of size [37] [38]. The logistics industry is labor-intensive and capital-intensive. There may be deviations in measuring the scale based only on the number of employees. Enterprise sales data fluctuate significantly due to occasional factors such as market demand and are only disclosed in listed enterprises. The firm size emphasized in this paper is the allocation level of the production factors. Total assets, as a kind of financial capital, can scientifically reflect and monitor the production factor resources existing in the enterprise and provide decision-makers with information about resource allocation [39]. Considering the data availability, this paper uses registered capital instead of the total asset to measure the firm size [40]. Based on China's classification criteria for small and medium-sized enterprises, considering the quality of business registration data of logistics enterprises, the registered capital of 100,000 and below, 100,000 to 5 million, 5 million to 10 million, above 10 million, respectively represent micro-, small-, medium- and large-sized logistics enterprises.

\section{Results and Discussion}

\subsection{Descriptive Statistical Analysis}

1) Degree of diversification of all-sized logistics enterprises 
Figure 3 shows descriptive statistics of the degree of enterprise diversification in Chongqing from 1982 to 2016. From 1982 to 1996, the changes in the level of diversification are not significant due to the small number of logistics enterprises. After Chongqing became the only municipality directly under the Central Government in West China in 1997, the logistics industry developed rapidly, with an average annual increase of 256.5 enterprises. Overall, the change in the average level of unrelated diversification and related diversification of all enterprises was stabilized, with the former increasing from 2.12 to 2.41 and the latter from 1.10 to 1.16 . In terms of the changes in the four diversified groups, the percentage of enterprises in the low-diversified group declined at an average annual rate of $16.32 \%$, the percentage of enterprises in the high-diversified group increased at an average annual rate of $14.23 \%$, and the percentage of enterprises in the related-diversified group changed little and remained stable. As for the percentage of enterprises in the unrelated diversified group, it shows an inverted U-shaped trend, reaching a peak of $27.95 \%$ in 2009 and then declining.

2) Degree of diversification of different-sized logistics enterprises

Figure 4 shows the diversified distribution of micro-, small-, medium- and

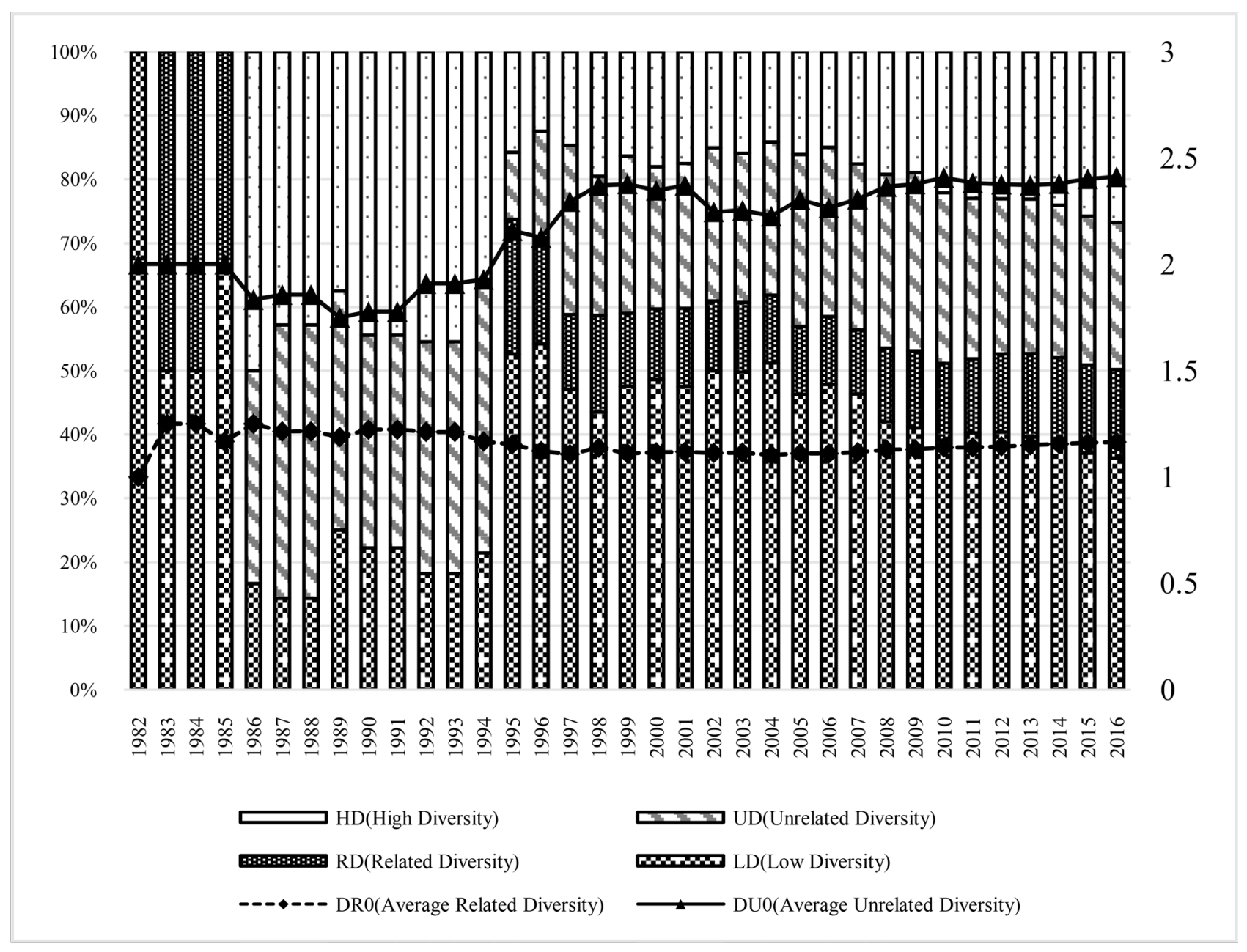

Figure 3. Types of diversification of logistics enterprises in Chongqing. 


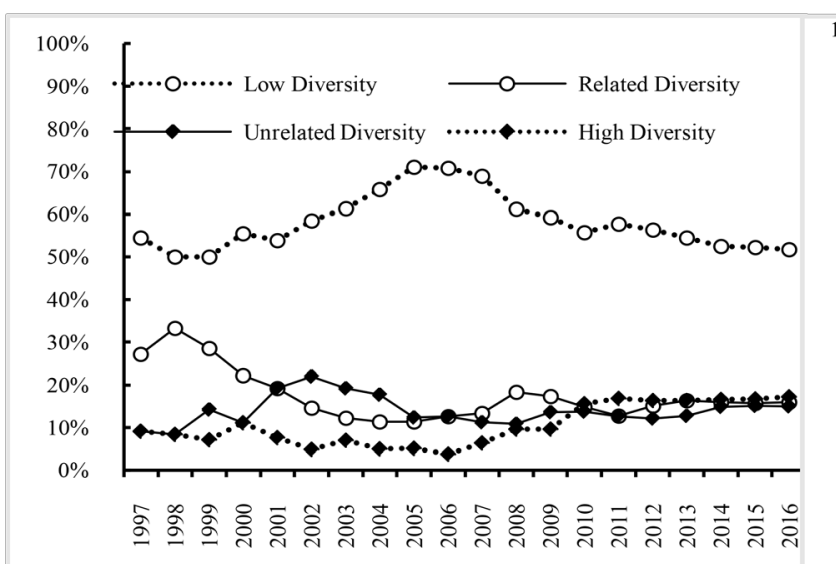

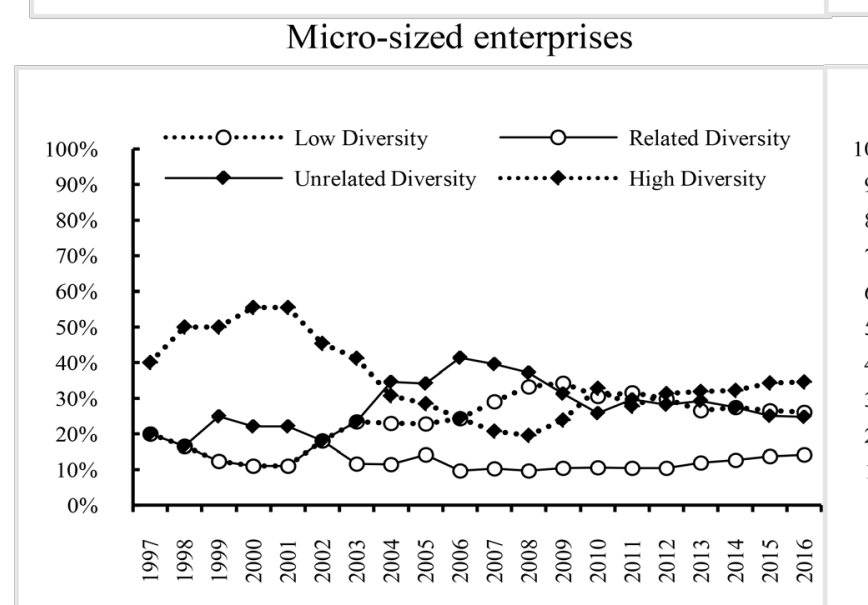

Medium-sized enterprises
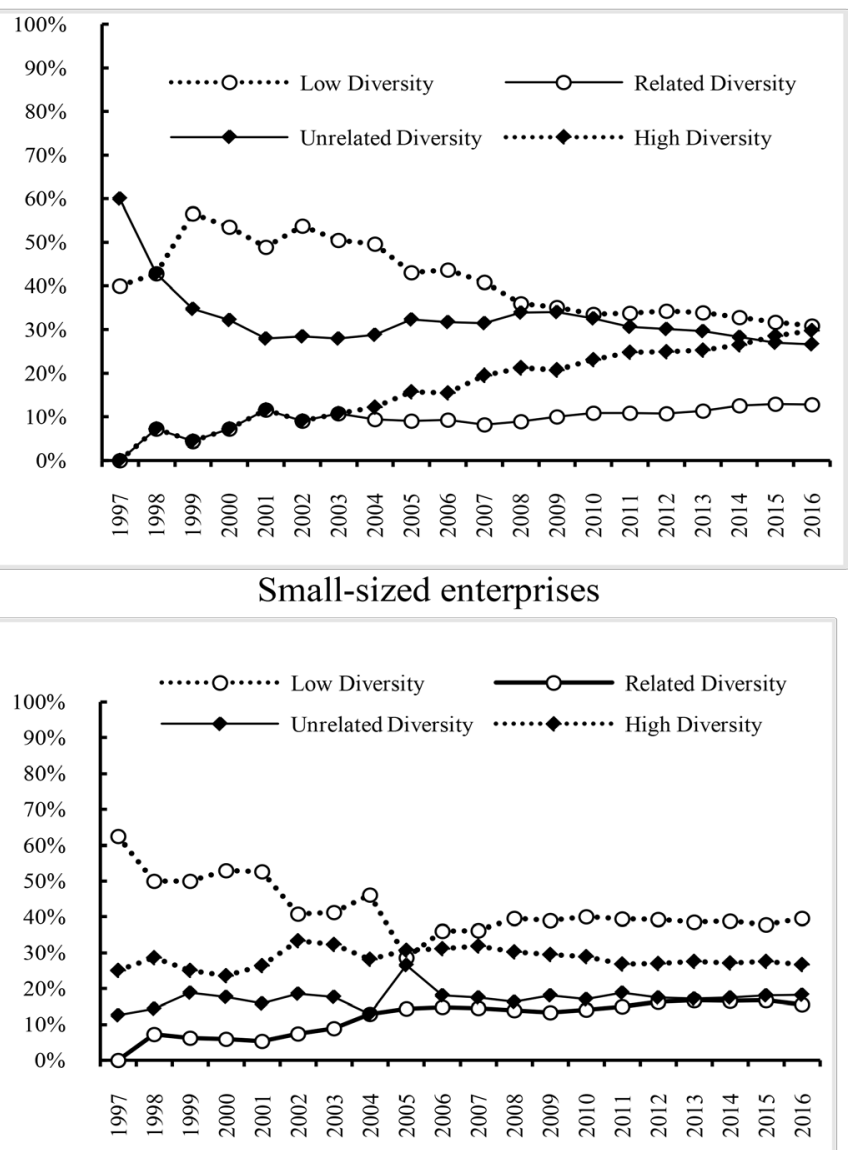

Large-sized enterprises

Figure 4. Changes in the degree of diversification in logistics enterprises of different sizes.

large-sized logistics enterprises from 1982 to 2016.

In micro-sized enterprises, the average proportion of low diversification increased from 56.21 percent (1997-2004) to 71.13 percent in 2005 and then decreased to 55.1 percent (2009-2016), the average proportion of unrelated and high diversification grew slowly (average annual growth rates are 0.3 percent and 0.4 percent respectively). In small-sized enterprises, the proportion of low and unrelated diversification has declined slowly (the average annual decline rate is $1.3 \%$ and $0.4 \%$ respectively). As for medium-sized enterprises, from 1997 to 2008, the proportion of the low diversification and unrelated diversification has increased rapidly (overall growth rates were 20 percent and 17 percent respectively), while the proportion of the related diversification and high diversification has declined significantly (overall decline rate were 10 percent and 27 percent respectively). From 2009 to 2016, the proportion of related diversification and high diversification has grown slowly (average annual declines rate were 0.5 percent and 1.4 percent, respectively), while the proportion of low diversification and unrelated diversification has declined slowly (average annual declines rate were 1.5 percent and 0.9 percent respectively). For large-sized enterprises, from 1997 through 2016, the proportion of low diversification decreased by about 20 percent, the proportion of related diversification increased by approximately 16 
percent. The proportion of unrelated diversification and high diversification fluctuated between $15 \%-19 \%$ and $26 \%$ - 30\%, respectively, and remained stable.

In general, all enterprises have been moving toward high diversification (average annual growth rates are $14.23 \%$ ). Before 2008, the trends of diversified development in large and medium-sized enterprises were more diverse and did not show consistent characteristics. Subsequently, small and medium-sized enterprises developed toward relevant diversification and high diversification, micro-sized enterprises developed toward unrelated diversification and high diversification, and large enterprises were more stable in all four diversification directions.

\subsection{Hypothesis Test Results}

1) The relationship between the firm size and the degree of enterprise diversification

To determine whether there is a correlation between the firm size and the degree of enterprise diversification, a regression analysis is performed on the sample data of 5923 enterprises registered. We used OLS to test hypotheses, which were developed by Legendre and Legendre [41]. The OLS is a widely used technique for estimating the parameters of a linear regression model. Chen and Ho [11] advised analyzing the relationship between diversification and firm size by OLS regression analysis. Based on the above literature and theoretical hypothesis, we constructed the following regression equations to test the relationships in the theoretical model:

$$
\text { diversifition }_{i}=\alpha_{0}+\beta \ln \_ \text {scale }_{i}+\varepsilon_{i}
$$

This article adapts the statistical software, Stata 12.0, to carry out the data analysis, the descriptive statistics of the variables, the correlation analysis among the variables and the regression analysis. The detailed analytical procedure is as follows: Model 1-1 consider the impact on the firm size on the total diversification, and independent variable is d; Model 1-2 consider the impact on the firm size on the unrelated diversification, and independent variable is du; Model 1-3 consider the impact on the firm size on the related diversification, and independent variable is dr. Table 2 reports the estimated results of the relationship

Table 2. Regression analysis of the impact of the scale of logistics enterprises on the degree of diversification.

\begin{tabular}{cccc}
\hline \multirow{2}{*}{$\begin{array}{c}\text { Independent } \\
\text { variables }\end{array}$} & \multicolumn{3}{c}{ Dependent variables } \\
\cline { 2 - 4 } & $\mathrm{d}$ & $\mathrm{du}$ & $\mathrm{d}$ r \\
model 1-1 & model 1-2 & model 1-3 \\
\hline Ln_scale $(p)$ & $0.1225024^{* * *}$ & $0.0963777^{* * *}$ & $0.006724^{* * *}$ \\
& $(0.000)$ & $(0.000)$ & $(0.000)$ \\
Model $F(p)$ & $418.92^{* * *}$ & $456.39^{* * *}$ & $30.71^{* * *}$ \\
& $(0.000)$ & $(0.000)$ & $(0.000)$ \\
$R^{2}$ & 0.0661 & 0.0716 & 0.0052 \\
\hline
\end{tabular}

${ }^{* * *} p<0.01$. 
between firm size and total diversification, related diversification, and unrelated diversification. In Hypothesis $\mathrm{Hla}, \mathrm{H} 1 \mathrm{~b}$, the authors proposed that the firm size would positively affect the level of related diversification and unrelated diversification. Model 1-2 and Model 1-3 provide strong support for this hypothesis under the condition of $p=0.01$. This implies that firm size positively affects a firm's diversification operation, whether diversify into unrelated business or related business. The result is in line with previous research accomplished by previous studies [14] [18] [19] [23]. Thus, business owners or managers should take into account the implanting diversification strategy in expanding scale.

2) Degree of diversification of enterprises in different sizes

Even if there is a positive correlation between firm size and the degree of diversification, it remains to be seen whether this conclusion is still applied to the different-sized enterprises, especially for micro-and small-sized logistics enterprises. Therefore, regression analysis is performed on the relationship between the size and the degree of the total, unrelated and related diversification in micro-, small-, medium- and large-sized enterprises. The results are shown in Table 3 and Table 4, Table 5.

Model 2-1, Model 3-1, and Model 4-1 are used to explore the relationship between firm size and total diversification, the unrelated diversification, and the related diversification in large-sized logistics enterprises. Model estimation result shows that firm size is not related to the degree of total diversification, unrelated diversification, and related diversification. So, the $\mathrm{H} 2 \mathrm{a}$ is not supported.

Model 2-2, Model 3-2, and Model 4-2 are used to examine the relationship between firm size and total diversification, the unrelated diversification, and the related diversification in medium-sized logistics enterprises. In three models, the results showed that firm size is not related to the degree of total diversification, unrelated diversification and related diversification. So, the H2b isn't supported.

Table 3. Regression analysis of the impact of logistics enterprises of four sizes on the degree of total diversification.

\begin{tabular}{|c|c|c|c|c|}
\hline \multirow{3}{*}{$\begin{array}{c}\text { Independent } \\
\text { variables }\end{array}$} & \multicolumn{4}{|c|}{ Dependent variables } \\
\hline & \multicolumn{4}{|c|}{$\mathrm{d}$} \\
\hline & model 2-1 & model 2-2 & model 2-3 & model 2-4 \\
\hline Ln_large $(p)$ & $\begin{array}{c}-0.0260903 \\
(0.713)\end{array}$ & & & \\
\hline Ln_mid $(p)$ & & $\begin{array}{c}0.2093892 \\
(0.473)\end{array}$ & & \\
\hline Ln_small $(p)$ & & & $\begin{array}{c}0.1498597^{* * *} \\
(0.000)\end{array}$ & \\
\hline Ln_micro $(p)$ & & & & $\begin{array}{c}0.1122656^{* * *} \\
(0.000)\end{array}$ \\
\hline Model $F(p)$ & $\begin{array}{c}0.14 \\
(0.713)\end{array}$ & $\begin{array}{c}0.52 \\
(0.473)\end{array}$ & $\begin{array}{l}71.5^{* * *} \\
(0.000)\end{array}$ & $\begin{array}{c}13.81^{* * *} \\
(0.000)\end{array}$ \\
\hline$R^{2}$ & 0.0004 & 0.0016 & 0.0187 & 0.0089 \\
\hline
\end{tabular}

${ }^{* * *} p<0.01$. 
Table 4. Regression analysis of the impact of logistics enterprises of four sizes on the degree of unrelated diversity.

\begin{tabular}{|c|c|c|c|c|}
\hline \multirow{3}{*}{$\begin{array}{l}\text { Independent } \\
\text { variables }\end{array}$} & \multicolumn{4}{|c|}{ Dependent variables } \\
\hline & \multicolumn{4}{|c|}{$\mathrm{du}$} \\
\hline & model 3-1 & model 3-2 & model 3-3 & model 3-4 \\
\hline Ln_large $(p)$ & $\begin{array}{c}-0.0236482 \\
(0.661)\end{array}$ & & & \\
\hline Ln_mid $(p)$ & & $\begin{array}{c}0.1437173 \\
(0.514)\end{array}$ & & \\
\hline Ln_small $(p)$ & & & $\begin{array}{c}0.0982416^{* * *} \\
(0.000)\end{array}$ & \\
\hline Ln_micro $(p)$ & & & & $\begin{array}{c}0.1051925^{* * *} \\
(0.000)\end{array}$ \\
\hline Model $F(p)$ & $\begin{array}{c}0.19 \\
(0.661)\end{array}$ & $\begin{array}{c}0.43 \\
(0.514)\end{array}$ & $\begin{array}{l}54.9^{* * *} \\
(0.000)\end{array}$ & $\begin{array}{c}21.26^{* * *} \\
(0.000)\end{array}$ \\
\hline$R^{2}$ & 0.0006 & 0.0014 & 0.0144 & 0.0137 \\
\hline
\end{tabular}

${ }^{* * *} p<0.01$

Table 5. Regression analysis of the impact of logistics enterprises of four sizes on the degree of related diversity.

\begin{tabular}{|c|c|c|c|c|}
\hline \multirow{3}{*}{$\begin{array}{l}\text { Independent } \\
\text { variables }\end{array}$} & \multicolumn{4}{|c|}{ Dependent variables } \\
\hline & \multicolumn{4}{|c|}{$\mathrm{d} \mathbf{r}$} \\
\hline & model 4-1 & model 4-2 & model 4-3 & model 4-4 \\
\hline Ln_large $(p)$ & $\begin{array}{c}0.0026312 \\
(0.859)\end{array}$ & & & \\
\hline Ln_mid $(p)$ & & $0.0293714(0.608)$ & & \\
\hline Ln_small $(p)$ & & & $\begin{array}{c}0.0128874^{* * *} \\
(0.000)\end{array}$ & \\
\hline Ln_micro $(p)$ & & & & $\begin{array}{l}0.0015285 \\
(0.806)\end{array}$ \\
\hline Model $F(p)$ & $\begin{array}{c}0.03 \\
(0.8591)\end{array}$ & $\begin{array}{c}0.26 \\
(0.6081)\end{array}$ & $\begin{array}{c}12.74^{* * *} \\
(0.000)\end{array}$ & $\begin{array}{c}0.8056^{* * *} \\
(0.000)\end{array}$ \\
\hline$R^{2}$ & 0.0001 & 0.0008 & 0.0034 & 0 \\
\hline
\end{tabular}

${ }^{* * *} p<0.01$

Model 2-3, Model 3-3, and Model 4-3 are used to examine the relationship between firm size and total diversification, the unrelated diversification, and the related diversification in small-sized logistics enterprises. In three models, the results showed firm size is positively related to the degree of total, unrelated and related diversification. So, the $\mathrm{H} 2 \mathrm{c}$ is supported.

Model 2-4, Model 3-4, and Model 4-4 are used to test the relationship between firm size and total diversification, the unrelated diversification, and the related diversification in micro-sized logistics enterprises. In three models, the results showed that firm size is positively related to the degree of total diversification 
and the unrelated diversification but does not correlate with related diversification. So, the H2d is supported.

\section{Conclusions}

The research interest in this paper is primarily on the relationship between firm size and business diversification. In terms of factor production theory, small-sized enterprises are relatively weak in the human, material and financial resources and other relevant property, making it hard to achieve business synergies and market synergies, which both require a considerable investment [27]. Thus, most studies believe that small-sized enterprises should focus on their core business and implement professional strategies. Simultaneously, medium- and large-sized companies are suitable for developing diversification strategies in other areas. However, new evidence emerges from different-sized enterprises in the logistics industry.

For logistics firms with micro size, we have found that investing and leveraging their intangible resources to develop unrelated diversified business is a crucial way to increase their core competencies and achieve cross-business synergies in the changing market; for logistics firms with medium and large size, the expansion of the firm along with the dynamic allocation of production factors which may bring the growth of coordination and control costs of integrating different business units and costs on meeting a diversity of customer demands [27] [42]. Therefore, it is difficult to get positive net gains from diversification. Also, as Li and Chen [43] studied that successful enterprises exhibit less strategic change.

This study provides a guide for firms implementing diversification in practice. Only when the firm size remains at certain levels could the firms obtain positive outcomes from the diversification strategy, such as adding profitability and market value [44]. So managers need a reasonable grasp of the levels and types of diversification to avoid financial loss due to excessive expansion. Micro-and small-sized logistics firms can develop suitable diversification strategies based on the unique resources they have. Also, if they cannot effectively control cost, medium- and large-sized logistics enterprises will find it very difficult to benefit from diversification.

Research limitations of this study are further acknowledged, leading to suggested directions for future research. Methodologically, due to the limitations of the research objects, the data here were based on the logistics business in which the company was involved. The method was simply numerically counting the number of businesses and failure to recognize differences in the size distribution of businesses. If data are available, future research should assign a weight to the business at the appropriate level. Besides, the degree of business diversification is the result of a combination of multiple factors. Future research also could incorporate more influencing factors into the research to obtain more insights into corporate diversification. 


\section{Conflicts of Interest}

The authors declare no conflicts of interest regarding the publication of this paper.

\section{References}

[1] Rivera, L., Sheffi, Y. and Knoppen, D. (2016) Logistics Clusters: The Impact of Further Agglomeration, Training and Firm Size on Collaboration and Value Added Services. International Journal of Production Economics, 179, 285-294. https://doi.org/10.1016/j.ijpe.2016.05.018

[2] Singh Rajesh, K., Garg Suresh, K. and Deshmukh, S.G. (2008) Strategy Development by SMEs for Competitiveness: A Review. Benchmarking: An International Journal, 15, 525-547. https://doi.org/10.1108/14635770810903132

[3] Geringer, J.M., Tallman, S. and Olsen, D.M. (2000) Product and International Diversification among Japanese Multinational Firms. Strategic Management Journal, $21,51-80$. https://doi.org/10.1002/(SICI)1097-0266(200001)21:1<51::AID-SMJ77>3.0.CO;2-K

[4] Colpan, A.M. (2006) Dynamic Effects of Product Diversity, International Scope and Keiretsu Membership on the Performance of Japan's Textile Firms in the 1990s. Asian Business \& Managemen, 5, 419-445. https://doi.org/10.1057/palgrave.abm.9200193

[5] Palepu, K. (1985) Diversification Strategy, Profit Performance and the Entropy Measure. Strategic Management Journal, 6, 239-255. https://doi.org/10.1002/smj.4250060305

[6] Chen, Y., Luo, D.L. and Li, W.W. (2014) Political Connections, Entry Barriers, and Firm Performance. Chinese Management Studies, 8, 473-486. https://doi.org/10.1108/CMS-08-2013-0148

[7] Mahoney, J.T. and Pandian, J.R. (1992) The Resource-Based View within the Conversation of Strategic Management. Strategic Management Journal, 13, 363-380. https://doi.org/10.1002/smj.4250130505

[8] Grant, R.M. (1991) The Resource-Based Theory of Competitive Advantage: Implications for Strategy Formulation. California Management Review, 33, 114-135. https://doi.org/10.2307/41166664

[9] Chatterjee, S. and Wernerfelt, B. (1991) The Link between Resources and Type of Diversification: Theory and Evidence. Strategic Management Journal, 12, 33-48. https://doi.org/10.1002/smj.4250120104

[10] Kochhar, R. and Hitt, M.A. (1998) Linking Corporate Strategy to Capital Structure: The Relationship between Diversification Strategy and Mode of Financing. Strategic Management Journal, 19, 601-610. https://doi.org/10.1002/(SICI)1097-0266(199806)19:6<601::AID-SMJ961>3.0.CO;2-M

[11] Chen, S.-S. and Ho, K.W. (2000) Corporate Diversification, Ownership Structure, and Firm Value: The Singapore Evidence. International Review of Financial Analysis, 9, 315-326. https://doi.org/10.1016/S1057-5219(00)00032-6

[12] Denis, D.J., Denis, D.K. and Sarin, A. (1997) Agency Problems, Equity Ownership, and Corporate Diversification. The Journal of Finance, 52, 135-160.

[13] Berglund (1999) Third-Party Logistics Is There a Future. International Journal of Logistics Management, 10, 59-70. https://doi.org/10.1108/09574099910805932

[14] Yusufoglu, Y. (2012) Diversification in the Dutch International Freight Forwarding Industry. Erasmus University Rotterdam, Rotterdam.

[15] Chang, S.J. and Singh, H. (1999) The Impact of Modes of Entry and Resource Fit on 
Modes of Exit by Multibusiness Firms. Strategic Management Journal, 20, 1019-1035.

https://doi.org/10.1002/(SICI)1097-0266(199911)20:11<1019::AID-SMJ66>3.0.CO;2-9

[16] Carbone, V. and Stone, M.A. (2005) Growth and Relational Strategies Used by the European Logistics Service Providers: Rationale and Outcomes. Transportation Research Part E: Logistics and Transportation Review, 41, 495-510. https://doi.org/10.1016/j.tre.2005.06.001

[17] Martha, L.C. (1999) Choosing a Third-Party Logistics Provider. World Trade, 12, 54.

[18] Lai, K.-H. (2004) Service Capability and Performance of Logistics Service Providers. Transportation Research Part E: Logistics and Transportation Review, 40, 385-399. https://doi.org/10.1016/j.tre.2004.01.002

[19] Markides, V. and Holweg, M. (2006) On the Diversification of International Freight Forwarders. International Journal of Physical Distribution \& Logistics Management, 36, 336-359. https://doi.org/10.1108/09600030610676231

[20] Makadok, R. (2001) Toward a Synthesis of the Resource-Based and Dynamic-Capability Views of Rent Creation. Strategic Management Journal, 22, 387-401. https://doi.org/10.1002/smj.158

[21] Cruijssen, F., Cools, M. and Dullaert, W. (2007) Horizontal Cooperation in Logistics: Opportunities and Impediments. Transportation Research Part E: Logistics and Transportation Review, 43, 129-142. https://doi.org/10.1016/j.tre.2005.09.007

[22] Andersson, D. (1995) Logistics Alliances and Structural Change.

[23] Hertz, S. and Alfredsson, M. (2003) Strategic Development of Third Party Logistics Providers. Industrial Marketing Management, 32, 139-149.

https://doi.org/10.1016/S0019-8501(02)00228-6

[24] Anholcer, M. and Kawa, A. (2018) Intangible Assets as a Source of Competitive Advantage for Logistics Service Providers. Transport Economics and Logistics, 78, 29-41. https://doi.org/10.26881/etil.2018.78.03

[25] Chen, H. and Chang, L. (2013) The Enlightenment of the Integration Mode of Foreign Small and Medium-sized Logistics Enterprises on China. Logistics Technology, 36, 62-64.

[26] Gunasekaran, A. and Ngai, E.W.T. (2003) The Successful Management of a Small Logistics Company. International Journal of Physical Distribution \& Logistics Management, 33, 825-842. https://doi.org/10.1108/09600030310503352

[27] Wu, D., Wu, X.B. and Zhou, H.J. (2012) International Expansion and Firm Performance in Emerging Market: Evidence from China. Chinese Management Studies, 6, 509-528. https://doi.org/10.1108/17506141211259168

[28] Zhang, Z. (2019) Research on the Problems and Countermeasures in the Development of Small and Medium-sized Logistics Enterprises. Shandong Normal University, Jinan.

[29] Lang, L., Stulz, R. and Tobin's, Q. (1993) Corporate Diversification and Firm Performance. Journal of Political Economy, 102, 1248-1280.

[30] Mukherji, A. (1998) The Relationship between Prior Performance and Diversification: A Study of Three Industries. Management Decision, 36, 180-188. https://doi.org/10.1108/00251749810208977

[31] Rawley, E. and Simcoe, T. (2010) Diversification, Diseconomies of Scope, and Vertical Contracting: Evidence from the Taxicab Industry. Management Science, 56, 1534-1550. https://doi.org/10.1287/mnsc.1100.1207 
[32] Xu, F. and Song, B. (2014) Enterprise Development Theory and Growth Mechanism. Southwest Jiaotong University Press, Chengdu.

[33] Li, G., Sun, W., Yuan, Q. and Liu, S. (2020) Planning versus the Market: Logistics Establishments and Logistics Parks in Chongqing, China. Journal of Transport Geography, 82, Article ID: 102599. https://doi.org/10.1016/j.jtrangeo.2019.102599

[34] Rivera, L., Sheffi, Y. and Welsch, R. (2014) Logistics Agglomeration in the US. Transportation Research Part A: Policy and Practice, 59, 222-238. https://doi.org/10.1016/j.tra.2013.11.009

[35] Hoskisson, R.E., Hitt, M.A., Johnson, R.A. and Moesel, D.D. (1993) Construct Validity of an Objective (Entropy) Categorical Measure of Diversification Strategy. Strategic Management Journal, 14, 215-235. https://doi.org/10.1002/smj.4250140305

[36] Varadarajan, P.R. and Ramanujam, V. (1987) Diversification and Performance: A Reexamination Using a New Two-Dimensional Conceptualization of Diversity in Firms. Academy of Management Journal, 30, 380-393.

[37] Symeonidis, G. (1996) Innovation, Firm Size and Market Structure: Schumpeterian Hypotheses and Some New Themes. Organisation for Economic Co-Operation and Development, Paris.

[38] Archibugi, D., Evangelista, R. and Simonetti, R. (1993) Concentration, Firm Size, and Innovation: Evidence from Innovation Costs. Technovation, 15, 153-163.

[39] Sun, X.H. and Wang, Y. (2014) The Impact of Firm Size on Productivity and Its Differences-An Empirical Study from Microdata of Industrial Firms. China Industrial Economics, No. 5, 57-69.

[40] Subramaniam, V. and Wasiuzzaman, S. (2019) Geographical Diversification, Firm Size and Profitability in Malaysia: A Quantile Regression Approach. Heliyon, 5, e02664. https://doi.org/10.1016/j.heliyon.2019.e02664

[41] Legendre, P. and Legendre, L. (1998) Numerical Ecology. Elsevier, Amsterdam.

[42] Chang, J.C. (2007) International Expansion Path, Speed, Product Diversification and Performance among Emerging-Market MNEs: Evidence from Asia-Pacific Multinational Companies. Asian Business \& Management, 6, 331-353. https://doi.org/10.1057/palgrave.abm.9200228

[43] Li, B. and Chen, S. (2019) Corporate-Level Strategy and Firm Performance: Evidence from China. Chinese Management Studies, 14, 1-14. https://doi.org/10.1108/CMS-10-2018-0715

[44] Arrighetti, A., Landini, F. and Lasagni, A. (2014) Intangible Assets and Firm Heterogeneity: Evidence from Italy. Research Policy, 43, 202-213.

https://doi.org/10.1016/j.respol.2013.07.015 